\title{
Delay in referral of rheumatoid arthritis patients to rheumatology clinic
}

Sahar Ahmed Saad ${ }^{1,2^{*}}$ and Najwa Khalil Alhaj ${ }^{3}$

\begin{abstract}
Background: Rheumatoid arthritis (RA) is an inflammatory connective tissue disease with both articular and extra articular manifestations. Early diagnosis and proper treatment affect strongly the patients' quality of life. In the early phase of the disease, effective treatment and strict monitoring would help to achieve remission within the shortest period. Delay in detection of these cases and consequently late referral to a rheumatologist result in loss of the golden time when effective treatment must start.

Results: Delay of patients' referral by the family physician was the most statistically significant factor responsible for the delay in starting of a specific therapy for RA.

Conclusion: Clear guidelines according to 2016 update of the EULAR recommendations for the management of early arthritis (Combe et al., Ann Rheum Dis 76:948-959, 2017) must be known to all primary care physicians to suspect RA and to avoid delay in referral of patients.
\end{abstract}

Keywords: Rheumatoid arthritis, Delay in referral, Primary care physicians

\section{Background}

Rheumatoid arthritis (RA) is not a simple benign disease. While some patients may recover without aggressive therapy, many of them do not, and those show erosive joint damage within the first 2 years of the disease $[1,2]$. Considering that about $90 \%$ of RA of patients suffers some degree of disability during the first two decades of onset, early detection and treatment of the disease is vital [3]. The first 90 days following the onset of RA symptoms are considered an important therapeutic window [4]. Treatment during this critical phase increases the chance of remission and reduces the possibility of joint damage and the need for joint replacement [5]. However, there are problems preventing early detection and active treatment including delay on side of the patient to seek medical advice, delay by a primary care doctor to suspect the diagnosis and then to refer the patient to the rheumatologist, and

\footnotetext{
* Correspondence: sahar.saad@khuh.org.bh

'Department of Rheumatology, King Hamad University Hospital (KHUH), Al Sayh, Bahrain

${ }^{2}$ Assiut University, Assiut, Egypt

Full list of author information is available at the end of the article
}

lastly the time lost in waiting to get an appointment with that specialized clinic.

\section{Methods}

A cohort of 66 patients diagnosed as having RA was studied between July 2013 and January 2014. Those cases were under treatment in the rheumatology clinic of King Hamad University Hospital that receives referrals from different resources. A questionnaire has been generated to be filled by patients enrolled in this study to get the following data:

* Patient's hospital number without his/her name

" Age in years and gender,

" Nationality: Bahraini or non-Bahraini,

" Level of education, employed or not, and special habits of medical importance such as smoking either active or passive

* Family history of arthritis

* Associated co-morbidities like diabetes, hypertension, and dyslipidemia,

\section{Springer Open}

(c) The Author(s). 2020 Open Access This article is licensed under a Creative Commons Attribution 4.0 International License, which permits use, sharing, adaptation, distribution and reproduction in any medium or format, as long as you give appropriate credit to the original author(s) and the source, provide a link to the Creative Commons licence, and indicate if changes were made. The images or other third party material in this article are included in the article's Creative Commons licence, unless indicated otherwise in a credit line to the material. If material is not included in the article's Creative Commons licence and your intended use is not permitted by statutory regulation or exceeds the permitted use, you will need to obtain permission directly from the copyright holder. To view a copy of this licence, visit http://creativecommons.org/licenses/by/4.0/. 
* Date of onset of musculoskeletal symptoms related to the current complaint,

* Date the patient has made appointment to see his/her general health care professional,

* Was the initial physician a General Practitioner (GP), Orthopedic surgeon, internist, an emergency doctor or any other?

* Number of visits the patient had before referral to a rheumatologist,

* Date of referral to a rheumatology clinic,

* Date of first appointment with the rheumatologist,

* Did the patient hear about RA?

If yes, from which of the following sources:

TV

Newspaper

Internet

A friend

Other sources

Inclusion criteria are patients who were diagnosed with RA according to 2010 ACR/EULAR criteria for diagnosing rheumatoid arthritis. Exclusion criteria are all other cases of arthritis other than RA were excluded.

Detailed information about patients and sources of referral were collected. Statistical analysis of all variables was done to find out where was the maximum delay in referral. Descriptives were computed. Count variables were analyzed using Chi-square tests. The association between the time taken to visit RA clinic and categorical variables has been studied by one-way independent student's test. Correlation analysis was done for time taken and number of visits. All reported $P$ values are twotailed and have been considered significant at $<0.05$.

\section{Results}

The study included 56 females (84.8\%) and 10 males (15.2\%) with an average age of 49 years (18-87 years). Bahraini patients were $65.2 \%$, non-Bahraini patients were $34.8 \%$ while majority of patients were educated (84.8\%).

Cases referred to rheumatology clinic by general practitioners (GPs) were 40 (60.6\%) while those referred by other doctors were $39.4 \%$. Also, $77.3 \%$ did not have information about RA, and majority of patients (78.8\%) had associated comorbid conditions with rheumatoid arthritis; hypertension and diabetes mellitus were the commonest among $60.6 \%$ of this series (40 patients).

\section{Detailed analysis}

The average delay between development of the first symptoms and presentation to Rheumatology Clinic was 20 months. An average number of visits of GP before referral was 4 visits (Table 1).

It seems that Bahraini people took somewhat lesser time to present to the rheumatology clinic compared to non-Bahraini patients. Also non-educated and unemployed patients took a relatively longer time to see the rheumatologist. However, there was no significant difference between the studied variables and time taken by the patients to reach the rheumatology clinic.

The average delay in referring patients from GP clinic to the rheumatology clinic (11.6 months) was statistically significant $P=0.003$ in comparison with the time taken by the patient to see his GP after development of first symptoms (7.4 months) and with time after referral to attend and meet the rheumatology consultant (1.89 months) (Table 2).

A cohort of 66 patients diagnosed as having RA

\section{Discussion}

RA is a disabling disease that negatively affects individuals and communities. Update information confirms the importance of early detection of the disease with start of DMARDs as soon as possible aiming at controlling disease activity to achieve remission [6].

Also, other studies showed that early consultation and therapy by a rheumatologist improve long-term outcomes and delay future orthopedic surgery [5].

The lag time between onset of RA and rheumatologic consultation can be divided into the following phases:

A. From onset of symptoms till reporting to a physician (patient's delay)

B. From consulting a physician till referral to a rheumatologist (physician's delay)

C. From referral to rheumatology appointment (hospital's delay)

A group of studies has been performed in different countries in a trial to measure the delay of referral of patients with RA and identify exactly where is the weak point or the phase that is responsible for this delay. Palm and Purinszky [7] in their report found that the median lag time between onset of RA and rheumatological encounter was 16 weeks. Women were referred significantly later than men (physicians delay median 10 weeks

Table 1 Correlations between time taken in months and number of visits

\begin{tabular}{lll}
\hline Number of visits made to health care professional before being referred to rheumatologist & $4.5 \pm 4.6$ & 0.219 \\
Time taken from first symptom to presenting to RA clinic & $20.5 \pm 21.9$ & 0.07 \\
\hline
\end{tabular}


Table 2 Time taken (in months) for the subjects from 1st symptom to seeing a GP, seeing the GP to being referred to RA clinic, and from date of referral to attending the RA clinic

\begin{tabular}{|c|c|c|c|c|}
\hline & $N$ & Mean (number of months) & Standard deviation & $P$ value \\
\hline Time taken from first symptom to seeing a GP & 54 & 7.4 & 15.3 & 0.003 \\
\hline Time taken after seeing a GP to getting referred & 54 & 11.6 & 15.6 & \\
\hline Time taken after getting referred from GP to attending RA clinic & 54 & 1.89 & 4.1 & \\
\hline
\end{tabular}

vs 3 weeks). The patient's delay and the hospitals' delay were a median of 4 weeks each. The authors considered the lag time was quite long for all patients considering the rheumatology service of five specialists for 240,000 inhabitants in Stotfold.

In our study, long-time referral of patients by the general health physicians was the most significant factor responsible for delay in starting their DMARD therapy.

There are great variations in referral times across Europe [8]. In one study, the average delay between starting of symptoms and referral was 17 months [9]; in a large study of 1674 patients with early RA, the majority of them were not seen by a rheumatologist within 3 months [10]. However, other smaller studies reported mean delay between 4 and 40 months [11, 12]. In Denmark, Jan and Merete [13] studied the reduction of lag time between onset of symptoms and diagnosis of patients with RA from year 2000 to 2011. The mean duration until diagnosis was 24 months in 2000-2002 while became about 4 months for whom who experienced initial symptoms in 2009-2011. The authors studied several factors similar to those explored in our study like age, gender, geographical regions, and data in registry system.

A recent research work included 197 patients, reported that $25 \%$ of patients waited 4 months or longer to see a rheumatologist; the reasons for delay were lack of patients' awareness about the disease and referring patients to non-rheumatologists [14].

Some of our results mimic those found by group of researchers in the UK last year [15]. Patients made an average of 4 GP visits before referral, and the median hospital delay was about 1 month similar to our findings. Also, the work of the UK showed that after onset of early RA symptoms, patients who purchased over-thecounter medications or used local ice/heat packs took longer time to request for a help than those who did not.

To our knowledge, the current study done in rheumatology unit of the center is the first in Bahrain to analyze the reasons in delay for diagnosis of patients with RA. To achieve the goal of early diagnosis, we adopt strategies during the past 2 years like public awareness programs, internet and website information, and educational sessions for family doctors to guide them for early identification and referral of patients. This policy has been implemented after analysis of our results in the current study.

These protocols showed success in decreasing time till diagnosis in many countries [15]. There is general agreement that early diagnosis of RA could be a difficult task for the general physician due to many reasons: clinical diagnosis of inflammatory arthritis is not always straight forward, classic features of RA take time to develop and many conditions can mimic inflammatory joint disease [16].

Serological tests should not be used as a guide for referral from primary health care centers, a recommendation made by Suresh [17] who found that about $66 \%$ of patients with a negative rheumatoid factor (RF) were excluded from referral to a consultant rheumatologist. So if general practitioners (GPs) rely wholly on clinical criteria and the RF test is restricted to rheumatologists only, we can expect improvement in consultant referrals. Also, a rheumatologist can order musculoskeletal ultrasonography to confirm the diagnosis of arthritis and determine if there is synovitis, erosion, and or power Doppler signals [18].

The study group in our work was relatively small which could explain non-significant statistical values. Also, it included patients when the rheumatology service started in the center, so a further study is planned to record effect of awareness programs held by this center for patients and general practitioners on reduction of time wasted before referral to rheumatology consultation. In addition, the time taken after visiting the rheumatology consultant and start of medication was not measured

\section{Conclusion}

Once RA is suspected, rapid referral to a rheumatologist is essential to start early treatment. There should be clear guidelines that help primary care physicians to suspect the disease hence to avoid long delay before hospital referral. Our suggestion is the EULAR/ACR classification for early diagnosis of the disease must be clear to the general practitioners [19].

\section{Abbreviations}

RA: Rheumatoid arthritis; RF: Rheumatoid factor; GPs: General practitioners
Acknowledgements

Not applicable 


\section{Authors' contributions}

SS initiated the idea of the research, collected the related references, and wrote the manuscript; N A shared in analysis and interpretation of the patient's data. All authors have read and approved the manuscript.

\section{Funding}

This study had no funding from any resource.

\section{Availability of data and materials}

Available on reasonable request from KHUH Patients of rheumatology clinic and their electronic medical records

\section{Ethics approval and consent to participate}

Research and Ethics committee at King Hamad University Hospital has approved this study (Committee's reference number is Ref. KHUH/Research/ No. 244/2018 dated 31 December 2018), and all patient were consented to participate verbally, and ethics committee approved this procedure.

\section{Consent for publication}

Not applicable

\section{Competing interests}

The authors declare that they have no competing interests.

\section{Author details}

'Department of Rheumatology, King Hamad University Hospital (KHUH), Al Sayh, Bahrain. ${ }^{2}$ Assiut University, Assiut, Egypt. ${ }^{3}$ Department of Internal

Medicine, King Hamad University Hospital, Al Sayh, Bahrain.

Received: 15 April 2020 Accepted: 18 May 2020

Published online: 17 August 2020

\section{References}

1. Mottonen T (1988) Prediction of erosiveness and rate of development of new erosions in early rheumatoid arthritis. Ann. Rheum. Dis 47:648-653

2. Van der Heijde DM (1995) Joint erosions and patients with early rheumatoid arthritis. Br J Rheumatol 34(suppl 2):74-78

3. Emery P, Breedveld FC, Dougadous M et al (2002) Early referral recommendation for newly diagnosed rheumatoid arthritis: evidence based development of a clinical guide. Ann Rheum Dis 61:290-297

4. Van Nies JA, Tsanak R, Gaujoux-Viala C et al (2015) Evaluating relationships between symptom duration and persistence of rheumatoid arthritis: does a widow of opportunity exist? Results on the Leiden early arthritis clinic and ESPOIR cohorts. Ann Rheum Dis 74:808-812

5. Feldman DE, Bernatsky S, Houde M et al (2013) Early consultation with a rheumatologist for RA: does it reduce subsequent use of orthopedic surgery. Rheumatology 52:452-459

6. Karim R, Christian D (2013) Rheumatoid arthritis: what do we mean by early? Rheumatology 52:411-412

7. Palm Q, Eparims ZY (2005) Women with early rheumatoid arthritis are referred late than men. Ann Rheum Dis 64:1227-1228

8. Raza K, Stack R, Kumar KT et al (2011) Delay in assessment of patients with rheumatoid arthritis: variation across Europe. Ann Rheum Dis 70:1822-1825

9. Hernandez-Garcia C, Vargas E, Abasolo L et al (2000) The lag time between onset of symptoms and access to rheumatology care and DMARD therapy in a cohort of patients with rheumatoid arthritis. J Rheumatol 27:2323-2338

10. Van Der Linden MP, Le Cessie S, Raza K, etal . (2010) Long term impact of delay in assessment of patients with early arthritis 62:3537-3546. Google Scholar

11. Chan KW, Felson DT, Yood RA et al (1994) The lag time between onset of symptoms and diagnosis of rheumatoid arthritis. Arthritis\&Rheum 37:814820

12. Rodriquez-Polanco E, Kuoy F et al (2011) Lag time between onset of symptoms and diagnosis in Venezuelan patients with rheumatoid arthritis. Rheumatol int. 31:657-665

13. Jan S, Merete L (2013) Diagnostic delay in patients with rheumatoid arthritis, psoriatic arthritis and ankylosing spondylitis (2015): results from the Danish nationwide DAN Bio registry. Ann Rheum Dis 74:e12. https://doi.org/10. 1136/Annrheumdis2048-67

14. Filip R, Anna K, Brygida K et al (2017) Diagnostic delays in rheumatic diseases with associated arthritis. Rheumatologia 55(4):169-176
15. Stack RJ, Nightingale $P$, Jinks $C$ et al (2019) Delays between the onset of symptoms and first rheumatology consultation in patients with rheumatoid arthritis in the UK: an observational study. BMJ open 9:e024361. https://doi. org/10.1136/bmjopen-2018-024361

16. Villeneuve $E, N a m ~ J L$, Jet BM et al (2013) A systemic literature review of strategies promoting early referral and reduction delays in the diagnosis and management of inflammatory arthritis. Ann Rheum. Dis 72:13-22

17. Suresh E (2004) Diagnosis of early rheumatoid arthritis: what the nonspecialist needs to know. J R Soc Med 97:421-424

18. Sarah O, Marina B (2015) Pro musculoskeletal ultrasonography in rheumatoid arthritis. Clin Exp Rheumatol 33:S50-S53

19. Combe B, Landewel R et al (2017) 2016 update of the EULAR recommendations for the management of early arthritis. Ann Rheum Dis 76 948-959

\section{Publisher's Note}

Springer Nature remains neutral with regard to jurisdictional claims in published maps and institutional affiliations.

\section{Submit your manuscript to a SpringerOpen ${ }^{\circ}$ journal and benefit from:}

- Convenient online submission

- Rigorous peer review

- Open access: articles freely available online

- High visibility within the field

- Retaining the copyright to your article

Submit your next manuscript at $\boldsymbol{\nabla}$ springeropen.com 